\title{
Low Voltage AC Arc Fault Test and Establishment of Database
}

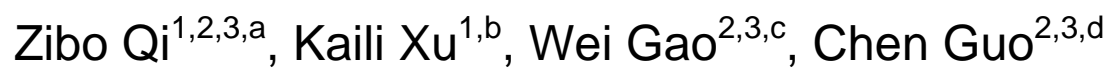

${ }^{1}$ College of Resources and Civil Engineering, Northeastern University, Shenyang 110819 , China; ${ }^{2}$ Shenyang Fire Research Institute of Ministry of Public Security, Shenyang 110034, China;

${ }^{3}$ Key Laboratory of Fire Scene Investigation and Evidence Identification, Ministry of Public Security, Shenyang 110034, China.

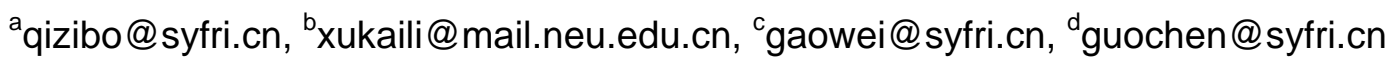

Keywords: AC, arc fault, simulation experiment, database

\begin{abstract}
. the situation is grim for domestic civil electrical fire and arc fault is the main cause of electrical fires. Low-voltage arc fault protection technology in China is still in infancy, and has not yet established a complete low-voltage arc fault database and the arc fault protection system is not perfect for electrical fires. Based on existing technology, this paper mainly established the arc fault test platform to carry out arc fault, suppression arc, malfunction and various experiments with cumulative 14,754 groups of tests. In the basis of wavelet analysis, phase-space reconstruction and fractal processing for experimental data analysis, the arc fault protection indicators suitable for Chinese power supply characteristics will be extracted and summarized and established an arc fault database with independent intellectual property rights. Through research and extract of scientific technical conditions and test methods, the technical support will be provided for relevant national standards preparation as well as the basic data for the development of early warning products.
\end{abstract}

\section{Introduction}

In recent years, the situation of civil building electrical fire is severe. According to the fire statistics of China Fire-fighting E-book of 2011, for the full year of 2010, 31.1\% of the total fires is electrical fires and the proportion increases by $0.9 \%$ compared with that of 2009 , showing an upward trend. There are more than 77 large fires throughout the year, among which 27 electrical fires are, accounting for $35.1 \%$ of the total, and the direct economic losses accounting for 14.8\% [1]. National Fire Protection Association (NFPA) states in the report of "Residential Building Fire Involved in Electrical Wiring and Lighting Equipment" in March 2008 that: there were about 20,900 residential building fires each year involving electrical wiring and lighting equipment in America between the year of 2002 and 2005 and about half of the fires were attributed to arc fault. National Electrical Code (NEC) estimates that about 40 percent of residential fires are caused by arc fault. Thus it can be seen, the share of electrical fires accounts for the largest proportion in all type of fires, and the enhancement of electrical protection for electrical equipment and prevention of electrical fires are inevitable requirements of social development. Arc fault is the main cause of electrical fires, and the severity of arc fault fires has been emphasized in various countries, particularly in Europe and America as well as other developed countries. American Arc Fault Circuit Interrupting Device Safety Standard UL1699 [2,3,4,5] began to be enforced since August 1, 2004, marking the official practical application stage of arc fault fire protection technology. Currently, America has developed an arc fault breaker, referred to as AFCI (Arc-fault Circuit interrupter) [6], for low-voltage circuit arc fault detection and circuit interrupting protection. In recent years, research institutions and manufacturers in China begin to develop and trial-manufacture Arc-Fault Detection Device (AFDD), and are committed to preparing the supporting standard for arc fault protection device installation and tests. The national standard of Code for Fireproofing Design of Electric in Civil Buildings mainly drafted by Shenyang Fire Research Institute adds the content of arc fault detector for specific places and equipment and the GB14287.4 Part 4 of Electrical Fire Monitoring System: Arc Fault Detection Device has now been completed and approved, expecting to come into within 2015. Arc Fault Detection Device (AFDD) 
Standard of Machinery Industry Standard in 2011 of Shanghai Electrical Apparatus Research Institute is currently being submitted for approval. This paper completed the Arc Fault Simulation Experiment and established a typical arc fault database. Through research and scientific technical conditions and test methods, the technical support will be provided for relevant national standards preparation as well as the basic data for the development of early warning products.

\section{Arc Fault Simulation Experiment}

Arc Fault Database Framework. Based on the arc incentives and their consequences, the arc can be categorized into work arc and arc fault. In order to support the national standard preparation of arc fault and development of related early warning products, arc fault database is mainly divided into typical arc fault, load suppression and malfunction. The first thing is to carry out simulation experiments of these three parts, collecting and recording test data. After data processing, the typical arc fault database will take shape.

Typical Arc Fault Test. According to different positions of arc fault, it can be divided into series and parallel arc fault; according to the cause of arc fault, there are three concluded reasons: insulation carbonation, air ionization caused by outer environment and short circuit. Therefore, we have developed a test device that is able to simulate the true reasons and types of arc fault. By using this device, parallel metallic contact arc fault tests, parallel carbonized path arc fault tests, series carbonized path arc fault tests and series point contact arc fault tests under conditions of $3 \mathrm{~kW}, 4 \mathrm{~kW}$, $6 \mathrm{~kW}, 8 \mathrm{~kW}$ and $10 \mathrm{~kW}$ with a power factor of $1.0,3 \mathrm{kVA}, 4 \mathrm{kVA}, 6 \mathrm{kVA}, 8 \mathrm{kVA}$ and $10 \mathrm{kVA}$ with a power factor of 0.7 and 0.3 , were carried out in accordance with the electrical system power and power factor. The total tests are 13,914 groups.

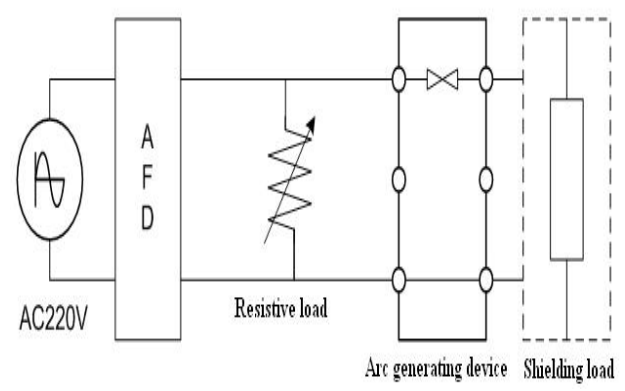

Fig.1 Schematic Load Arc Occurs in the Middle of Trial



Fig.2 Schematic Load Arc Occurs in the Front of Trial

Operation Inhibition Fault Test. In order to ensure the protective effect of early warning products in actual electrical system, we respectively select the microwave oven, induction cooker, capacitor filter, line impedance, air conditioner, cleaner, resistive load, electronic ballast fluorescent lamp and so on as inhibitory load, and test in a manner shown in the following Fig.1 to 2, collecting the arc fault voltage and current characteristics in above mentioned load. A total of 483 group tests were carried out.

Malfunction (in Normal Operation) Test. To prevent malfunction of early warning products in practical applications, we have studied the capacitor start motor, cleaner, induction cooker, microwave oven, hand drill by electronic variable speed, electric iron, infrared disinfection cabinet, inverter air conditioner, fluorescent lamp with electronic ballast, fluorescent lamp with inductive ballast and other single load, as well as computer, refrigerator, fluorescent lamp with inductive ballast, fixed-frequency air conditioner and normal operation with other mixed workloads, especially the start-instantaneous current and voltage waveforms. The test is conducted a total of 100 groups.

Through analysis of malfunction test results, hand drill, cleaner, microwave oven and inductive fluorescent lamp have a larger current effect under normal operation, which is reflected in the severe current waveform deformation and transferring from a sine wave into a triangle wave as well as other irregular shapes; electric iron, hand drill, inductive fluorescent lamp and some other electric device will produce normal arc during normal operation and the arc numbers are mainly distributed 
under the range of 13 per second.

\section{Arc Fault Analysis Data Analysis and Establishment of Database}

Arc Fault Current Phase Space Trajectories Diagram Fractal Dimension Calculation. After collecting and recording the simulation experiment data, the fractal processing on the data was conducted. Fractal's original intention is irregular, fractionary and fragmented, which is a kind of self-similar graphic, phenomenon or physical process. The study object of fractal theory is the rough and irregular geometric shape in natural nonlinear system. It starts from a complex nonlinear system and understands the inner regularity from the complicated and abstract subject itself, which can describe a complex object that can not be described quantitatively or difficult to be quantified by a convenient quantitative method. and thus has been widely applied in many areas.

There are many methods for calculating the fractal dimension in fractal geometry, some of which are classical calculation methods, such as self-similar dimension and Box-counting dimension, etc. Some other calculation methods are for the need of people's calculation and research and evolved from the classical algorithms combining with the actual situation, such as fractal method, area-perimeter method, RMS method and structure function method. The paper studies phase space trajectories of arc fault current using lower box dimension.

The program is written by matlab software for the calculation of fractal Box-counting dimension of current track in each half arc fault cycle and get the Box-counting dimension value. And then, the arc fault is divided into 5-6 categories according to the distribution value of arc fault Box-counting dimension under each load condition.By the same method, fractal processing and classification is conducted for arc fault data under other load conditions.

Arc Fault Database Framework. Due to the randomness and uncertainty of arc fault, we carry out the following test data processing to ensure that the test data in database can represent the arc fault characteristics under such a load condition and the arc fault number meets standard requirements:

According to the Box-counting dimension and arc classification results, a section test data is found out to make the arc fault number meet the standard requirements and these arc classification numbers include all classification numbers under such load conditions. This section data will be cut out in voltage zero crossing location by compiled program from the original data, the results are as shown in Fig. 3 to 4. Take Fig. 3 as an example, fractal Box-counting dimension in nine of half cycle arc fault is 1.6198, 1.6694, 1.6345, 1.7189, 1.6576, 1.7338, 1.7498, 1.6026 and 1.7022 respectively, which belongs to 3, 2, 5, 3, 5, 6, 1 and 4 level arc according to such arc fault classification.

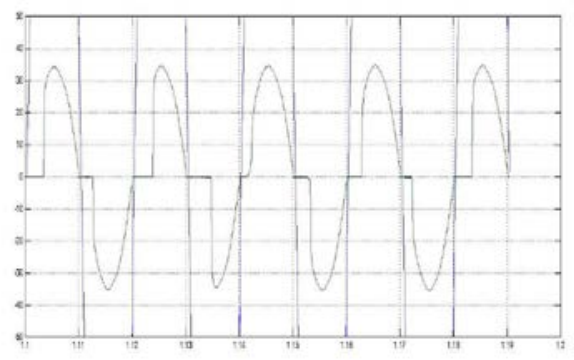

Fig. 3 Cutting Results for Series Connection of 9 Arc Fault Data

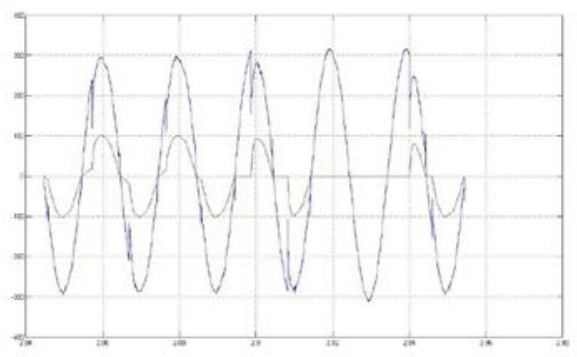

Fig. 4 Cutting Results for Parallel Connection of 9 Arc Fault Data

Add normal current and voltage waveforms in the front and rear respectively on the cut-out data by compiled stitching program to form a complete database data.

After the above process, the typical arc fault data is obtained and the arc fault database is established.

\section{Summary}

Low-voltage arc fault protection technology in China is still in infancy, and has not yet established a 
complete low-voltage arc fault database and the arc fault protection system is not perfect for electrical fires. Based on existing technology, this paper mainly established the arc fault test platform to carry out arc fault, suppression arc, malfunction and various experiments with cumulative 14,754 groups' tests. On the basis of wavelet analysis, phase-space reconstruction and fractal processing for experimental data analysis, the arc fault protection indicators suitable for Chinese power supply characteristics will be extracted and summarized, as well as establish an arc fault database with independent intellectual property rights. Through research and scientific technical conditions and test methods, the technical support will be provided for relevant national standards preparation as well as the basic data for the development of early warning products.

\section{References}

[1] Fire Department of Ministry of Public Security. China Fire-fighting E-book (2011) [M]. Beijing: International Culture Publishing House, 2011. 1-2.

[2] Chen Degui. Low Voltage Arc Fault Circuit Breaker - One New Low Voltage Protection Electrical Appliance [J]. Universal Low Voltage Electrical Appliance, 2007: 7-9.

[3] Yang Yi, Dong Aihua, Fu Yongli. Low Voltage Arc Fault Detection Overview [J]. Low Voltage Appliances, 2009 (5): 1-2.

[4] Wang Houyu. Design, Installation and Testing of Low Voltage Electrical Installations (Third Edition). Beijing: China Electric Power Press. 2012.

[5] Zou Yunfeng. Low Voltage Arc Fault Studies and Diagnostic [D]. Hangzhou: Zhejiang University, Master's Thesis, 2010.

[6] Mechler P. Simulation of AC Arc Faults in Aircraft Electrical Networks [C]. 21st International Conference on Electrical Contacts. Switzerland, 2002: 290-295. 